\title{
Analysis of Reserve Capacity and Subsequent Stenting in a Case of Subacute Occlusion of the Internal Carotid Artery
}

\author{
K. Kallenberg $\cdot$ J. Rühlmann $\cdot$ J. Baudewig $\cdot$ J. Larsen $\cdot$ \\ S. Gröschel $\cdot$ P. Dechent $\cdot$ A. Kastrup $\cdot$ M. Knauth
}

Received: 10 May 2012 / Accepted: 13 August 2012 / Published online: 8 September 2012

(C) The Author(s) 2012. This article is published with open access at Springerlink.com

\section{Introduction}

In stroke patients, an acute thrombotic occlusion of an internal carotid artery (ICA) is a poor predictor for clinical outcome [1]. It has occasionally been managed by carotid endarterectomy [2] (CEA) or percutaneous transluminal angioplasty (PTA) with [3] or without [4] stent protection (carotid angioplasty and stenting, CAS). On the other hand, a chronic thrombotic occlusion (CTO) of the ICA may be treated successfully by external-internal carotid artery (EC-

K. Kallenberg, M.D. ( $\bowtie) \cdot$ Dr. med. J. Rühlmann ·

Dr. J. Baudewig

Department of Neuroradiology, MR-Research in Neurology

and Psychiatry, University Medical Center Göttingen

Robert-Koch-Str. 40, 37099 Göttingen, Germany

e-mail: kai.kallenberg@med.uni-goettingen.de

Dr. J. Baudewig

Department of Diagnostic Radiology,

Christian-Albrechts-University Kiel, Kiel, Germany

Dr. med. J. Larsen

Department of Radiology, Evangelisches Krankenhaus

Göttingen-Weende, Göttingen, Germany

Dr. med. S. Gröschel

Department of Psychiatry and Psychotherapy, University Medical

Centre, Mainz, Germany

PD Dr. P. Dechent

Department of Cognitive Neurology, MR-Research in Neurology

and Psychiatry, Universitymedicine Göttingen, Göttingen, Germany

Prof. Dr. med. A. Kastrup

Department of Neurology,

Klinikum Bremen-Mitte, Bremen, Germany

Prof. Dr. med. M. Knauth

Department of Neuroradiology,

University Medical Center Göttingen, Göttingen, Germany
IC) bypass surgery $[5,6]$. However, EC-IC together with best medical treatment (BMT) does not reduce the risk of an ipsilateral stroke compared with BMT alone [7]. In addition, there have also been recent reports on CAS in patients with symptomatic CTO $[8,9]$ and CAS has a serious role in patients with high operative risk.

We herein report on the diagnostic work-up and subsequent therapeutic management of a patient with symptomatic thrombotic occlusion of the left extracranial ICA and a pre-existing occlusion of the contralateral ICA [10].

\section{Case Report}

A 65-year-old male with multiple cardiovascular risk factors presented with dysarthria and central right-sided facial palsy following an episode of syncope. The patient was admitted to our stroke unit where he experienced blood pressure-dependent right-sided weakness and sensorimotor aphasia, initially controllable by conservative therapy.

Pre-Interventional Assessment

Computed tomography (CT)-angiography (CTA; Aquilion, Toshiba Medical Systems Europa, Zoetermeer, Niederlande) showed bilateral ICA occlusion and the magnetic resonance (MR) scan on a 3Tesla MR-system (TIM TRIO ${ }^{\text {, }}$ Siemens Medical Solutions, Erlangen, Germany) demonstrated multiple chronic microvascular lesions bilaterally on T2-weighted images. Diffusion-weighted imaging (DWI) revealed acute infarctions in a watershed distribution with additional significant prolongation of both the mean transit time (MTT) and time to peak (TTP) in the left hemisphere. Conventional catheter angiography (digital subtraction angiography, DSA) finally confirmed the diagnosis of bila- 


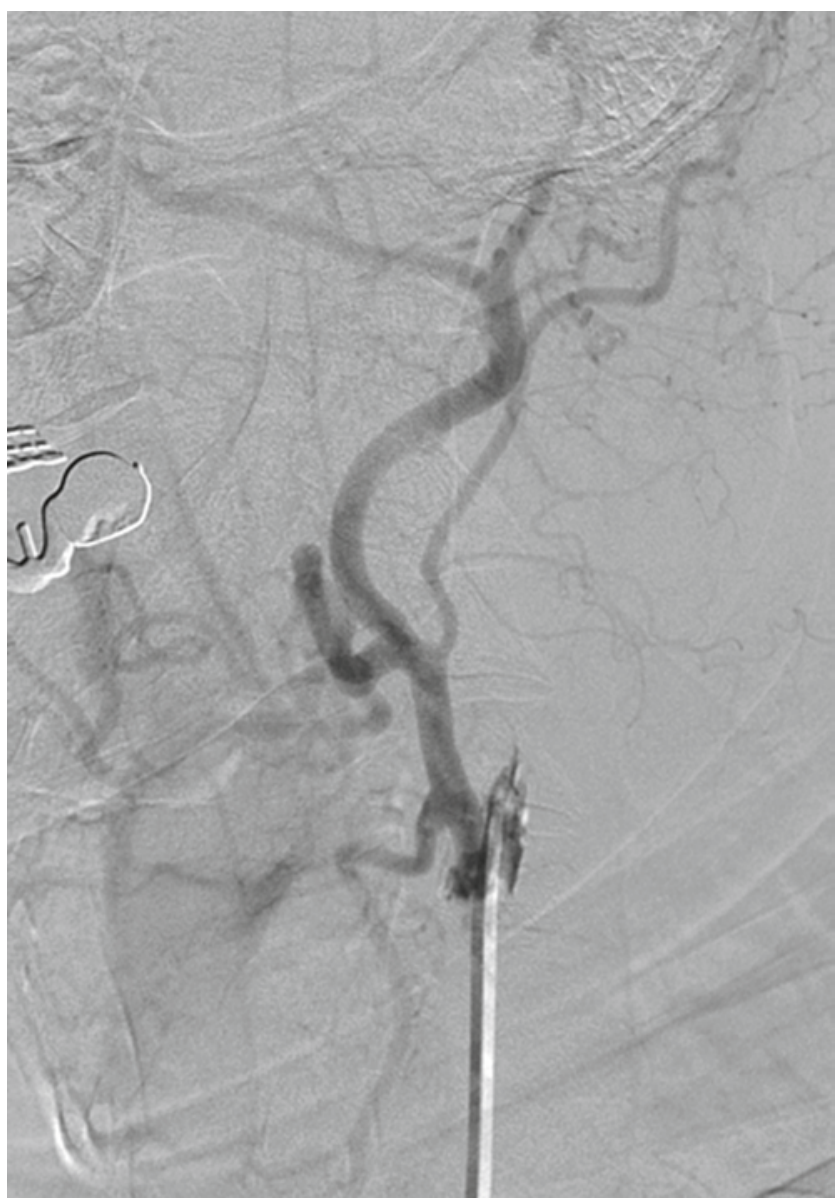

Fig. 1 Catheter angiography (DSA) demonstrates complete occlusion of the left internal carotid artery

teral ICA occlusion (Fig. 1) and revealed collateralisations via the ophthalmic arteries as well as via vertebro-basilar pathways. Importantly, origin and subsequent course of the left external carotid artery (EC) were found to be entirely normal and an EC-IC bypass was considered accordingly.

Given the patient's recurrent symptoms, assumingly of hemodynamic origin, an urgent intervention was required. To further support such a decision, a Blood Oxygenation $L$ evel Dependent MR scan was obtained (Fig. 2) to evaluate the patient's cerebrovascular reserve capacity (CRV) [11, 12]: The experimental set-up had previously been approved by the local ethics committee and included a bottled carbon dioxide $\left(\mathrm{CO}_{2}\right)$ source and a dedicated magnetic resonance imaging (MRI) patient-monitoring device (GE Medical Systems Information Technologies, Freiburg, Germany). The patient was prepared with a conventional facial nonrebreathing mask and a gas bag connected for a $3 \mathrm{~min}-\mathrm{CO}_{2}$ challenge to induce hypercapnia.

The analysis of BOLD signal intensity changes was performed using an in-house software package (Brainshow [13]). The BOLD response was diminished in the left hemisphere, mainly in the middle cerebral artery (MCA) territory, thus indicating a marked reduction of reserve capacity (Fig. 2).

\section{Intervention}

The patient was treated with $100 \mathrm{mg}$ aspirin p. o. before admission. Then, he was given an additional $75 \mathrm{mg}$ clopidogrel p. o. and because of the fluctuating symptoms the aspirin dosage was raised to $300 \mathrm{mg}$ and also low-dose heparin was administered.

Eight days following the initial event, the patient's symptoms suddenly deteriorated irrespective of maximum conservative therapy. Since emergency EC-IC bypass surgery was not possible logistically, the patient agreed to attempt a neuroendovascular revascularisation. Written informed consent was obtained and stent-protected CAS performed. In addition to the established anticoagulation, further heparin was given via intravenous infusion during the procedure (activated clotting time, ACT $=250-300 \mathrm{~s}$ ).

Selective left common carotid artery catheterisation was performed according to standard aseptic technique using a guide-wire (Terumo, Tokyo, Japan) and a 7F guide catheter (Mach 1 19M, Boston Scientific, Natick/MA, USA). A microcatheter (FastTracker 18 ${ }^{\mathrm{TM}}$, Boston Scientific, Natick/ MA, USA) with a 0.014-in guide-wire (Synchro 14; Boston Scientific, Natick/MA, USA) was utilised to carefully negotiate the lumen of the occluded vessel under biplanar fluoroscopic control to a level beyond the occlusion; intraluminal position confirmed by microcatheter series. A 7/40 Carotid Wallstent ${ }^{\mathrm{TM}}$ Monorail ${ }^{\mathrm{TM}}$-System (Boston Scientific, Natick/MA, USA) was then deployed, followed by balloon angioplasty using a 5/20 Sterling ${ }^{\mathrm{TM}}$ balloon catheter (Boston Scientific, Natick/MA, USA) at an inflation pressure of 8 bar.

The final angiogram series demonstrated a small intimal flap distal to the stent indicating a minor dissection which was considered to be adequately treated by the present anticoagulation regimen. However, we attributed the very small post-interventional diameter of the extracranial ICA primarily to the previous collapse (Figs. 3 and 4). The vessel diameter was monitored by duplex-ultrasound and normalised within $48 \mathrm{~h}$. The control CT-angiography after 1 week confirmed a patent vessel diameter and the very small intimal flap which finally healed without any additional interventional treatment.

The patient's subsequent course was uneventful. His preinterventional neurological symptoms subsided. Follow-up MRI showed no new infarct. Cerebral perfusion as well as CRV (Fig. 2) improved markedly. A follow-up CTA examination of the carotid arteries at 3 months revealed persistence of excellent luminal reconstruction without recurrent stenosis. 
Fig. 2 Representative supratentorial slices prior to (left) and after (right) carotid artery stenting show a significant difference in hypercapniainduced BOLD signal intensity changes between the hemispheres: an initial restriction (left) and the subsequent improvement (right) can be clearly seen in the left MCA territory of cerebrovascular reactivity
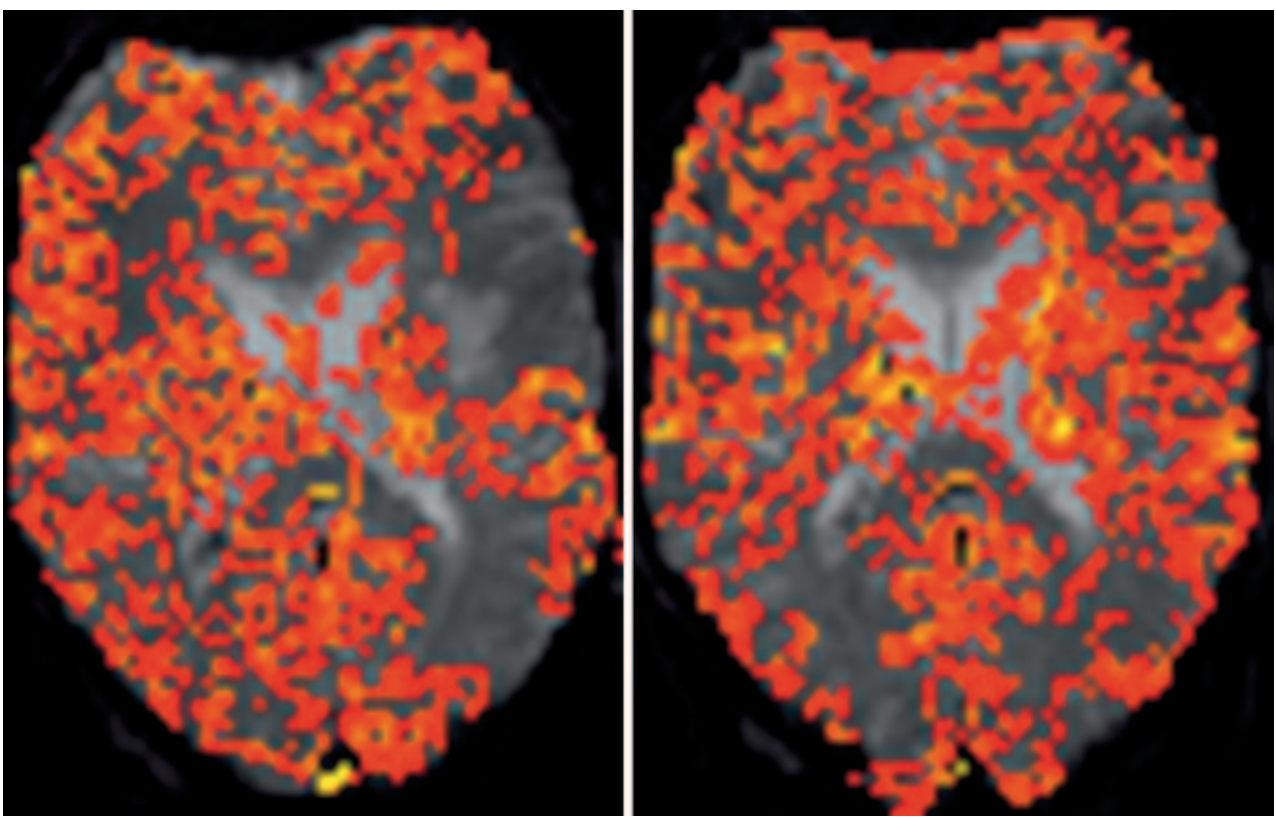

Fig. 3 Catheter angiography images showing successful left internal carotid artery (LCI) revascularisation with anterograde filling of MCA branches after stenting and stent position (un-subtracted image)
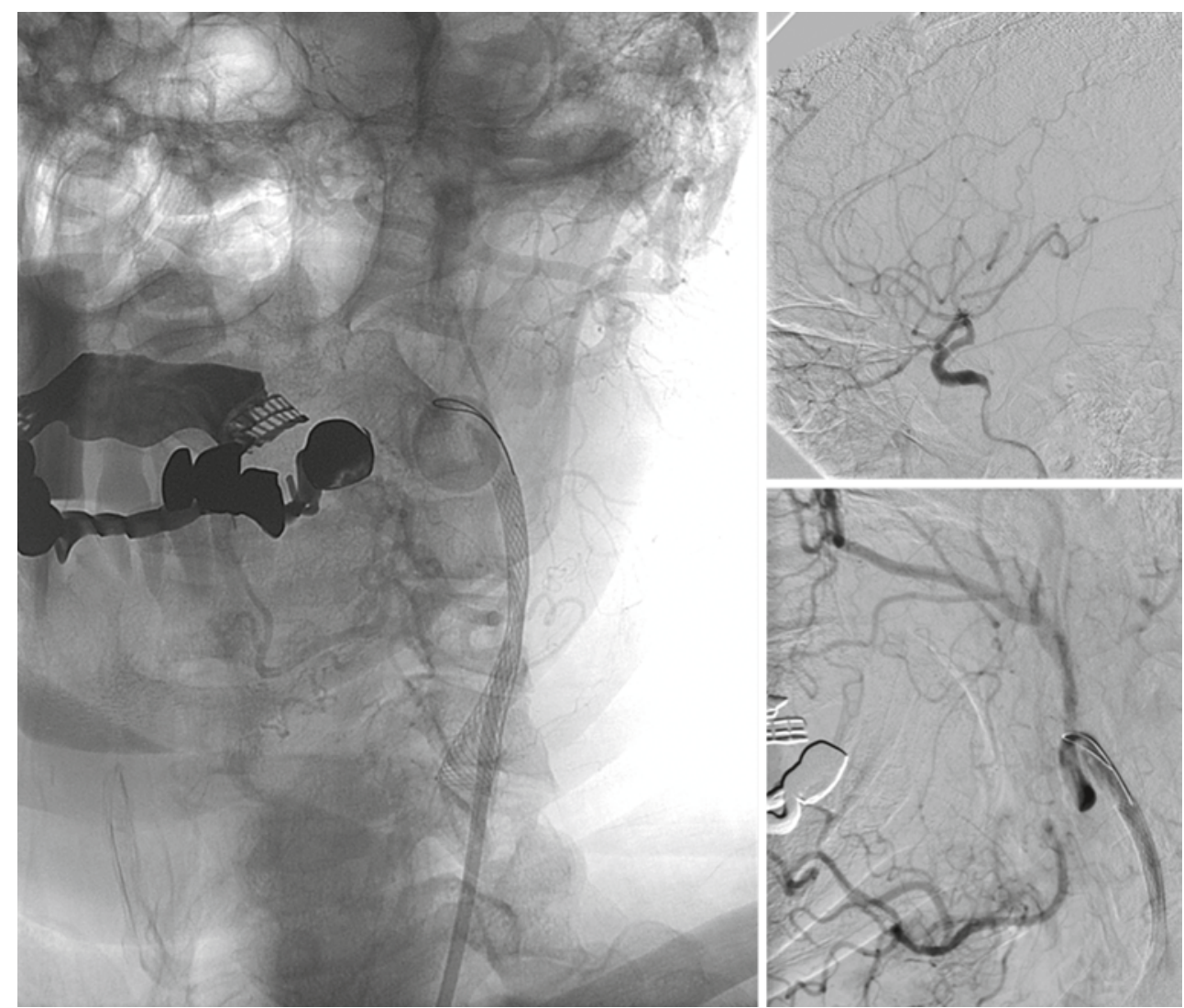

After the neurointerventional procedure the anticoagulation regimen was maintained for 1 week and then reduced to $100 \mathrm{mg}$ aspirin and $75 \mathrm{mg}$ clopidogrel for 3 months. The patient is on $100 \mathrm{mg}$ aspirin since.

\section{Discussion}

In the setting of acute or chronic carotid artery occlusion, cerebral ischemia may principally result from either embolic occlusion with resulting territorial ischemia or from reduced 


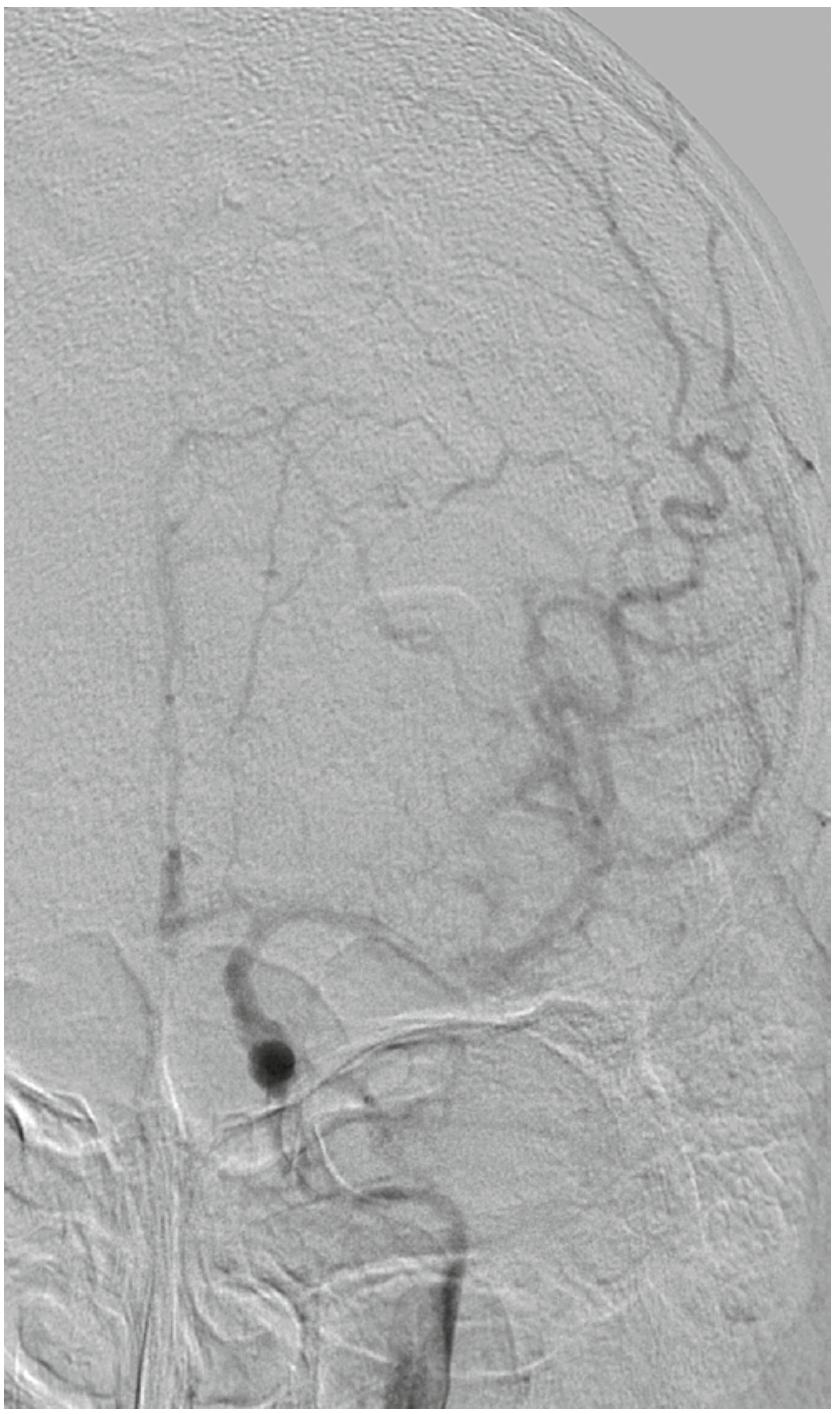

Fig. 4 The post-interventional DSA image in frontal view shows the filling of the ipsilateral MCA (image quality is considerably diminished as the patient was only minimally sedated for the procedure and became progressively agitated)

regional perfusion with consequent hemodynamically distributed infarcts. While the value of thrombolysis and fibrinolysis in the acute setting has been shown to be beneficial [14], the mechanism underlying the acute deterioration in our case was rather due to hypoperfusion rather than thromboembolism. EC-IC bypass has been reported in a selected group of patients with poor reserve capacity when CEA was not possible [6]. In our case, EC-IC bypass appeared appropriate but was not applicable because of the acuteness of the patient's deterioration. Paty et al. [15] reported on success rates of CEA of the order of $30 \%$ when performed within 14 days after the onset of symptoms. Furthermore, successful CAS [16] and stent-assisted revascularisation of intracranial vessels [17] in a subacute stage had been reported.
In patients with co-existing conditions leading to a higher operative risk, CAS is not inferior to CEA [10]. However, at this particular time, there is no scientific evidence for the sufficient safety of endovascular revascularisation of totally occluded ICAs.

Measurement of CRV by the means of Xenon-CT has been suggested as a surrogate parameter when selecting patients for cerebrovascular therapy [18]. Alternatively, the applicability of $\mathrm{CO}_{2}$ exposure-induced hypercapnia in combination with BOLD-contrast functional MR has been demonstrated [11, 19, 20]. Considering our patient's symptoms and his restricted cerebrovascular reserve, an attempt of revascularisation was indicated.

Taking the risk of distal embolisation into account, a blood flow manipulation with proximal balloon occlusion of the common carotid artery was discussed before the intervention but not taken into account because it would not have added any benefit as long as external artery branches were still open [21]. Furthermore, it would have led to a flow reversal in the ophthalmic artery with the threat of a steal phenomenon and unpredictable consequences. The only double-balloon device available in our department has a very small lumen which seemed inappropriate in the present setting. In addition, the pre-operative work-up for the ECIC bypass demonstrated a substantial contribution from the external carotid artery to the brain perfusion. Any further reduction of arterial input should be avoided under those precarious circumstances. The contrast injection through the microcatheter showed no relevant thrombus load in the ICA distal to the occlusion - in this case the procedure would have had to be adjusted, e.g. applying vacuum thrombectomy $[22,23]$.

In the past, several reports of reperfusion injury following recanalisation by either CEA [24-26] or CAS [27, 28] have led to a very careful selection of patients, especially in cases with prolonged ischemia. For this reason, initial therapy in our patient comprised medical therapy with anticoagulation as well as blood-pressure elevation only. However, this approach did not yield a satisfactory result: symptoms were fluctuating and aggravated over time. Following further deterioration with sudden onset of aphasia and hemiparesis, an ultima ratio decision was therefore made to attempt neuroendovascular revascularisation.

CAS in subacute ICA occlusion is feasible and may lead to a favourable outcome but should be restricted to carefully selected cases. The non-invasive assessment of cerebrovascular $\mathrm{CO}_{2}$ reactivity using BOLD-contrast MRI might provide valuable information in this setting.

Acknowledgements The authors (K. Kallenberg, J. Baudewig and P. Dechent) were supported by the Volkswagen Stiftung (Grants ZN1635 and ZN 2193). 
Financial Disclosure The authors (K. Kallenberg and M. Knauth) state the following financial disclosures: Speakers Bureau (K. Kallenberg [Acandis, Pforzheim/Germany] and M. Knauth [Penumbra, Alameda/USA; Siemens Healthcare, Erlangen/Germany; Acandis, Pforzheim/Germany; Codman, Norderstedt/Germany]).

Conflict of Interest The authors declare that there is no actual or potential conflict of interest in relation to this article.

Open Access This article is distributed under the terms of the Creative Commons Attribution License which permits any use, distribution, and reproduction in any medium, provided the original author(s) and the source are credited.

\section{References}

1. Bhatia R, Hill MD, Shobha N, Menon B, Bal S, Kochar P et al. Low rates of acute recanalization with intravenous recombinant tissue plasminogen activator in ischemic stroke: real-world experience and a call for action. Stroke. 2012;41(10):2254-8.

2. Moran JM, Reichman OH, Baker WH. Staged intracranial and extracranial revascularization. Arch Surg. 1977;112(12):1424-8.

3. Bockenheimer SA, Mathias K. Percutaneous transluminal angioplasty in arteriosclerotic internal carotid artery stenosis. AJNR Am J Neuroradiol. 1983;4(3):791-2.

4. Diethrich EB, Ndiaye M, Reid DB. Stenting in the carotid artery: initial experience in 110 patients. J Endovasc Surg. 1996;3(1):42-62.

5. O'Hara PJ, Hertzer NR, Beven EG. External carotid revascularization: review of a ten-year experience. J Vasc Surg. 1985;2(5):709-14.

6. Nussbaum ES, Erickson DL. Extracranial-intracranial bypass for ischemic cerebrovascular disease refractory to maximal medical therapy. Neurosurgery. 2000;46(1):37-42; (discussion 3).

7. Powers WJ, Clarke WR, Grubb RL Jr., Videen TO, Adams HP Jr., Derdeyn CP. Extracranial-intracranial bypass surgery for stroke prevention in hemodynamic cerebral ischemia: the Carotid Occlusion Surgery Study randomized trial. JAMA. 2011;306(18):1983-92.

8. Komiyama M, Yoshimura M, Honnda Y, Matsusaka Y, Yasui T. Percutaneous angioplasty of a chronic total occlusion of the intracranial internal carotid artery. Case report. Surg Neurol. 2006;66(5):513-8; (discussion 8).

9. Terada T, Yamaga H, Tsumoto T, Masuo O, Itakura T. Use of an embolic protection system during endovascular recanalization of a totally occluded cervical internal carotid artery at the chronic stage. Case report. J Neurosurg. 2005;102(3):558-64.

10. Yadav JS, Wholey MH, Kuntz RE, Fayad P, Katzen BT, Mishkel GJ, et al. Protected carotid-artery stenting versus endarterectomy in high-risk patients. N Engl J Med. 2004;351(15):1493-501.

11. Kastrup A, Kruger G, Glover GH, Neumann-Haefelin T, Moseley ME. Regional variability of cerebral blood oxygenation response to hypercapnia. Neuroimage. 1999;10(6):675-81.

12. Ziyeh S, Rick J, Reinhard M, Hetzel A, Mader I, Speck O. Blood oxygen level-dependent MRI of cerebral $\mathrm{CO}_{2}$ reactivity in severe carotid stenosis and occlusion. Stroke. 2005;36(4):751-6.
13. Baudewig J, Dechent P, Merboldt KD, Frahm J. Thresholding in correlation analyses of magnetic resonance functional neuroimaging. Magn Reson Imaging. 2003;21(10):1121-30.

14. del Zoppo GJ, Poeck K, Pessin MS, Wolpert SM, Furlan AJ, Ferbert A, et al. Recombinant tissue plasminogen activator in acute thrombotic and embolic stroke. Ann Neurol. 1992;32(1):78-86.

15. Paty PS, Adeniyi JA, Mehta M, Darling RC 3rd, Chang BB, Kreienberg PB, et al. Surgical treatment of internal carotid artery occlusion. J Vasc Surg. 2003;37(4):785-8.

16. Imai K, Mori T, Izumoto H, Takabatake N, Kunieda T, Yamamoto $\mathrm{S}$, et al. Successful stenting seven days after atherothrombotic occlusion of the intracranial internal carotid artery. J Endovasc Ther. 2006;13(2):254-9.

17. Kelly ME, Turner RD, Moskowitz SI, Gonugunta VR, Rasmussen PA, Masaryk TJ, et al. Revascularization of symptomatic subacute cerebrovascular occlusions with a self-expanding intracranial stent system. Neurosurgery. 2009;64(1):72-8; (discussion 8).

18. Yamashita T, Urakawa M, Yasuda H, Matayoshi Y. Measurement of cerebral reserve capacity using acetazolamide loading xenon CT CBF before carotid endarterectomy. J Neuroradiol. 2005;32(5):329-31.

19. Riecker A, Grodd W, Klose U, Schulz JB, Groschel K, Erb M, et al. Relation between regional functional MRI activation and vascular reactivity to carbon dioxide during normal aging. J Cereb Blood Flow Metab. 2003;23(5):565-73.

20. van Der Zande FH, Hofman PA, Backes WH. Mapping hypercapnia-induced cerebrovascular reactivity using BOLD MRI. Neuroradiology. 2005;47(2):114-20.

21. Palombo G, Stella N, Fantozzi C, Bozzao A, Taurino M. Transcranial doppler and diffusion-weighted magnetic resonance evaluation of cerebral embolization occurring during transfemoral carotid stenting with proximal flow blockage. J Cardiovasc Surg (Torino). 2012. Epub ahead of print.

22. Hwang YH, Kang DH, Kim YW, Kim YS, Park SP, Suh CK. Outcome of forced-suction thrombectomy in acute intracranial internal carotid occlusion. J Neurointerv Surg. 2012. doi:10.1136/ neurointsurg-2012-010277.

23. Kang DH, Hwang YH, Kim YS, Park J, Kwon O, Jung C. Direct thrombus retrieval using the reperfusion catheter of the penumbra system: forced-suction thrombectomy in acute ischemic stroke. AJNR Am J Neuroradiol. 2011;32(2):283-7.

24. Piepgras DG, Morgan MK, Sundt TM Jr., Yanagihara T, Mussman LM. Intracerebral hemorrhage after carotid endarterectomy. J Neurosurg. 1988;68(4):532-6.

25. Pomposelli FB, Lamparello PJ, Riles TS, Craighead CC, Giangola G, Imparato AM. Intracranial hemorrhage after carotid endarterectomy. J Vasc Surg. 1988;7(2):248-55.

26. Solomon RA, Loftus CM, Quest DO, Correll JW. Incidence and etiology of intracerebral hemorrhage following carotid endarterectomy. J Neurosurg. 1986;64(1):29-34.

27. Meyers PM, Higashida RT, Phatouros CC, Malek AM, Lempert TE, Dowd CF, et al. Cerebral hyperperfusion syndrome after percutaneous transluminal stenting of the craniocervical arteries. Neurosurgery. 2000;47(2):335-43; (discussion 43-5).

28. Buhk JH, Cepek L, Knauth M. Hyperacute intracerebral hemorrhage complicating carotid stenting should be distinguished from hyperperfusion syndrome. AJNR Am J Neuroradiol. 2006;27(7):1508-13. 